\title{
Parametric Study for High-Frequency, High-Intensity Ultrasonics in Removal of Sub-Micron Particles
}

\author{
Vetrimurugan, J. Michael Goodson, and Terry Lim
}

\begin{abstract}
In this paper, we describe an experimental study undertaken to investigate ultrasonic and megasonic fields in the frequency range $25 \mathrm{kHz}-360 \mathrm{kHz}$, temperature range $30{ }^{\circ} \mathrm{C}-$ $70{ }^{\circ} \mathrm{C}$ and re-circulation range $0-10 \mathrm{GPM}$ with respect to their surface cleaning and erosion potential. Measurements are performed using three different methods - LPC, cavitation intensity and aluminium foil test - to assess these mechanisms mainly for disk drive components. Conclusions are drawn regarding the nature of interactions between high-frequency, high-intensity ultrasonic fields and temperature. Recommendations are provided for optimal settings to maximize surface cleaning for variety of disk drive components.
\end{abstract}

Index Terms-Ultrasonic cleaning, megasonic cleaning, LPC, removal efficiency, cavitation intensity, erosion rate.

\section{INTRODUCTION}

The rapid advancements in various current technologies such as Heat Assisted Magnetic Regarding (HAMR) and the constant trend in miniaturization of the disk drive components such as sliders and so on have created the need for higher cleanliness level. Contaminant in the level of sub-micron can cause scratches on the media, alters Fly Height (FH) and also induce corrosion in the sliders used in disk drive industries (leads to disk drive failures) [1]-[3]. Removal of these contaminants is important to achieve higher yield. Ultrasonic and megasonic cleaning is widely used to remove sub-micron and nano- dimensional contaminants effectively from various surfaces. In order to achieve higher cleanliness optimization of this cleaning process parameter is so important. There are several parameter affects the performance of ultrasonic cleaning which includes frequency, sonication power, basket orientation, basket material, temperature, re-circulation rate and so on. So, for every material it is necessary to find the optimum parameter settings to achieve higher cleanliness. Among all the parameters, temperature is the most important single parameter to be considered in maximizing cleaning performance. This is because so many liquid properties affecting cavitation intensity are related to temperature. The changes in temperature result in changes in viscosity, weakens the adhesion strength of the contaminant, the solubility of gas in the liquid, the diffusion rate of dissolved gasses in the liquid, and vapor pressure, all of which affect cavitation intensity [4], [5]. Cavitation intensity gradually decreases

Manuscript received January 15, 2014; revised May 27, 2014.

Vetrimurugan is with the Advanced Ceramics Technology (M) SDN BHD, no. 1536, Jalan Perusahaah, Bukit Tengah Ind Park, India (e-mail: janet@act.crestm.com). with increase of temperature for De-Ionized (DI) water. Cavitation intensity will drop drastically when the temperature of the medium approaches the boiling point of the liquid [6]-[8]. Traditional ultrasonic theory suggests that the best temperature for use in an ultrasonic cleaning system is typically $65 \%$ of the boiling point of the solution [9]. Although this formula has been used as a general guideline to determine optimum temperatures for decades, in reality it rarely plays a role in determining optimum temperatures for any given application. Temperatures are usually related more to the effectiveness of the cleaning agent in use rather than the effectiveness of the ultrasonic cleaning system. Each cleaning fluid may have an optimum temperature at which it performs best.

In this paper the effect of temperature, frequency and re-circulation rate on sub-micron particle removal was studied.

\section{EXPERIMENTS}

The experiments are conducted using Crest standard tanks and Crest Console systems with various frequencies. All experiments were performed in a Class 1000 Cleanroom of the Advanced Ceramics Lab, Malaysia. The cavitation intensity for various frequencies was measured by using ppb TM cavitation meter. The frequency used for this study was 58 kHz, $68 \mathrm{kHz}, 132 \mathrm{kHz}, 58 / 132 \mathrm{kHz}$ (Patented Technology) and $360 \mathrm{kHz}$ (Megasonic Sweep Technology). The ranges of temperature studied for each frequency was $30-75{ }^{\circ} \mathrm{C}$. The re-circulation range studied was $0-10 \mathrm{GPM}$. The volume of the ultrasonic tank used for re-circulation study was 5 gallons and 10 gallons. The parts used for this study was E-Coated DSP (one of the disk drive components) and they came from the same batch of material so that the initial cleanliness level was approximately the same. The parts were washed with different frequencies, temperatures and then subjected to LPC extraction to find the residual particles in the parts. For each frequency, the experiments were repeated three times and the average of this value was taken to plot the temperature vs particle counts, frequency vs particle counts and flow rate vs particle counts.

The frequency used for final extraction was $132 \mathrm{kHz}$ with 60 watts/gallon. The ultrasonic extraction method utilizes ultrasonic energy to extract particles from a part and the particle concentration in the extraction solution was measured using liquid particle counter (LPC). The particle counter used for this study was particle measuring system $\left(\mathrm{PMS}^{\mathrm{TM}}\right)$ and LiQuilaz SO2. This counter can measure the particle sizes from $0.2 \mu \mathrm{m}$ to $2 \mu \mathrm{m}$. The size of the particles reported for this study was $>0.3 \mu \mathrm{m}$. 


\section{RESULTS AND DiSCUSSION}

\section{A. Effect of Temperature and Re-Circulation Rate on Cavitation Intensity}

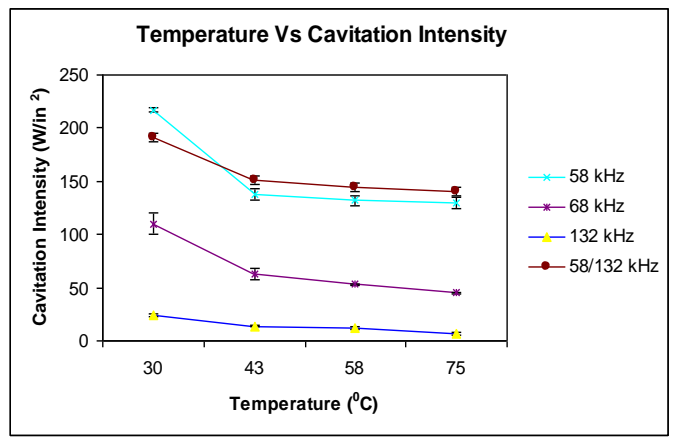

Fig. 1. Effect of temperature on cavitation intensity for various ultrasonic frequencies.

The effect of temperature on cavitation intensity and re-circulation rate on cavitation intensity for various frequencies is shown in Fig. 1 and Fig. 2. From Fig. 1, it can be observed that the cavitation intensity decreases with increase of temperature for various frequencies. The reduction in cavitation intensity is steeper until $\sim 45 \mathrm{deg} C$ and then its decreases more gradually. The cavitation intensity also decreases with increase of frequency. The cavitation intensity is inversely related to ultrasonic frequency. As the ultrasonic frequency increases, the cavitation intensity decreases because of the smaller sizes of the cavitation bubbles and their resultant less violent implosion. Increasing temperature can causes a reduction in the intensity of ultrasound required for the formation of cavitation bubbles. This is probably due to reduction in surface tension and/or viscosity of the liquid, either of which would lead to a reduction in the cohesive forces within the fluid and the energy required to tear it apart.

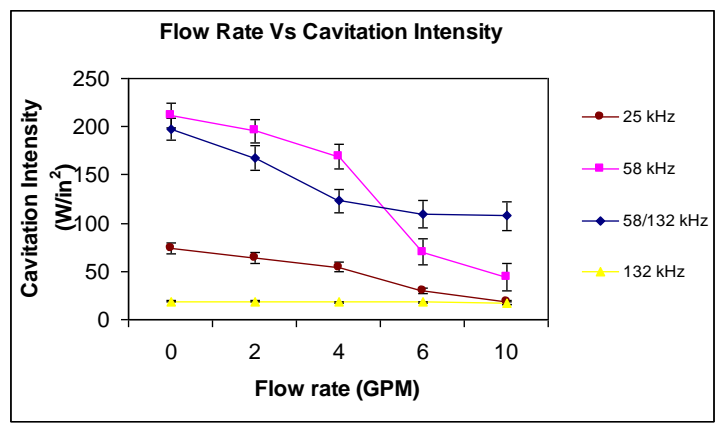

Fig. 2. Effect of re-circulation rate on cavitation intensity for various ultrasonic frequencies.

Effect of re-circulation rate on cavitation intensity for various frequencies is shown in Fig. 2. The cavitation intensity was measured in 9 different locations of the tank and the spatial average was taken to plot the graph. The purpose of doing re-circulation is to remove the solid particles from the cleaning solution thereby keep the solutions as pure as possible. If not, the particle slowly accumulates in the cleaning solution and renders re-deposition of particles on the parts. Re-circulation can be done mainly by three different ways i.e 1. Sonic on - re-circulation off 2. Sonic off re-circulation on 3. Sonic on - re-circulation on. Normally, most of the customers follow only first two ways to remove the particles from the cleaning tank. In fully automated machine, the basket arrival to the cleaning tank is continuous process and therefore the ' $\tau$ ' (residence time) is not sufficient enough to remove/control the particle accumulates in the cleaning tank.

where, the $\tau$ is defined as follows,

$$
\tau=[\text { Capacity of the system/rate of flow of the system }](1)
$$

From Fig. 2, it can be observed that the cavitation intensity decreases with increase of flow rate. The cavitation intensity (sonic activity) was affected more for lower frequencies compared to higher frequencies $(132 \mathrm{kHz})$. It seems that the re-circulation rate until $2-3$ gallons/min $(\sim 25 \%$ of the total volume of the tank) there is not much drop in cavitation intensity but after 4 gallons/min the cavitation intensity drops almost linearly with increase of flow rate. At low re-circulation rate the flow become laminar, hence it won't affects the formation of cavitation bubbles but at high flow rate the flow become turbulent. The turbulence caused by the high re-circulation rate affects the formation of cavitation bubbles. Another important thing is that the time taken to form cavitation bubble is almost 3-4 times higher for low frequencies $(25 \mathrm{kHz}$ ) compared to higher frequencies (132) $\mathrm{kHz}$. This is the reason why lower frequencies are affected more with increase of re-circulation rate as compared to higher frequencies.

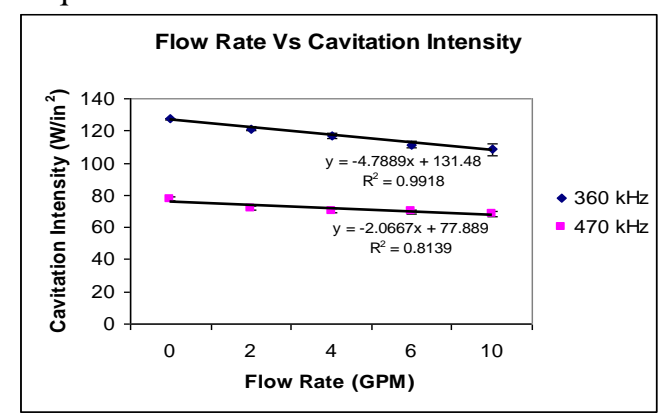

Fig. 3. Effect of re-circulation rate on cavitation intensity for various megasonic frequencies.

The effect of flow rate on cavitation intensity for various megasonic frequencies is shown in Fig. 3. From Fig. 3, it can be seen that the cavitation intensity decreases very gradually with increase of flow rate. The loss of cavitation intensity with increase of re-circulation rate is higher for ultrasonic frequencies compared to megasonic frequencies.

\section{B. Effect of Temperature and Re-Circulation Rate on Particle Removal}

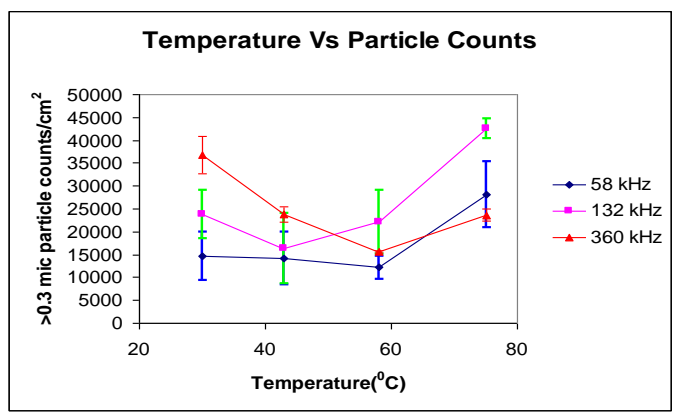

Fig. 4. Effect of temperature on cleaning for various frequencies. 
The parts are cleaned with different frequencies and various temperatures and then it was subjected to $132 \mathrm{kHz}$ LPC extraction. The particle count obtained for various frequencies with different temperature is shown in Fig. 4. From Fig. 4, it can be observed that the particle count decreases with increase of temperature until $60{ }^{\circ} \mathrm{C}$ (Maximum cleaning efficiency) and then it starts increases (cleaning efficiency drops). This is due to the fact that the temperature around $50-60{ }^{\circ} \mathrm{C}$ the adhesion force mainly due to Van der Waals force between the particles and the substrate weakens and therefore the particles attached to the surface can easily be removed. Once the temperature reaches $60{ }^{\circ} \mathrm{C}$ the particle count starts increases (drops in cleaning efficiency). This is due to significant increase of vapor pressure, hence leads to formation of vaporous cavitation. So, whilst high temperature favors the nucleation of cavities and the presence of liquid vapor within the bubble leads to a cushioning of the implosion during the compression cycle. Hence stable cavitation is favored and the impact of ultrasound is reduced, as the shock wave released on cavity implosion becomes less intense. So, the particle removal efficiency is also reduced for temperature above $60{ }^{\circ} \mathrm{C}$.

Increase in temperature makes it easier to go below the point of vaporization so the cavitation initiate with less energy. The number of cavitation events will increase as the temperature is increased but the energy being stored in the cavitation bubble will decrease. As the temperature increases the cavitation intensity steadily diminishes and cease or becomes ineffective for most cleaning applications at the boiling point of the liquid. So, the balancing of temperature and cavitation is important to achieve higher cleaning efficiency.

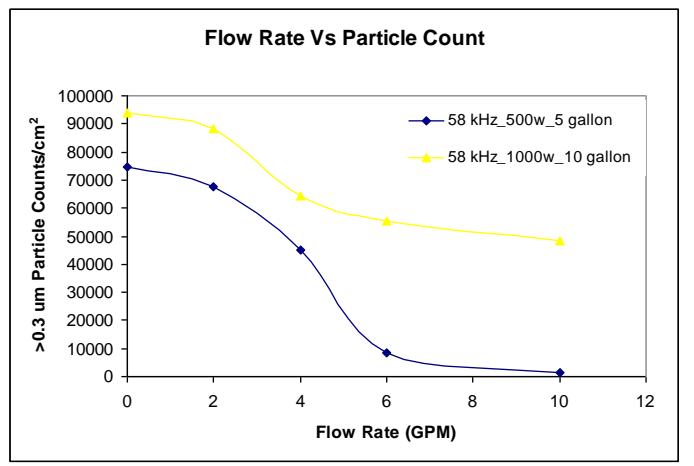

Fig. 5. Effect of re-circulation rate on cleaning for ultrasonic frequency $58 / 132 \mathrm{kHz}$.

The effect of flow rate on particle counts obtained for 58 $\mathrm{kHz}$ with 5 gallons tank $(500 \mathrm{~W})$ and 10 gallon tank $(1000 \mathrm{~W})$ is shown in Fig. 5. From Fig. 5, it can be observed that the increase in flow rate decreases the cleaning efficiency of the system. The drop in cleaning efficiency of the system is more for 5 gallons tank compared to 10 gallons tank. Even though, the watts/gallon is same (100 W/gallon) for both tanks but it behaves differently with increase of flow rate in terms of cleaning efficiency. It can be observed that the effect of flow rate on cleaning efficiency mainly depends on volume of the tank rather than watts/gallon used. It can also be observed that when sonic on conditions during parts cleaning, the re-circulation rate would be $\sim 20-25 \%$ of the total volume of the tank. If we go more than that the cleaning efficiency will be affected more. The sudden drop in particle counts (from Fig. 5) indicates the flow transfer from transition to turbulent.

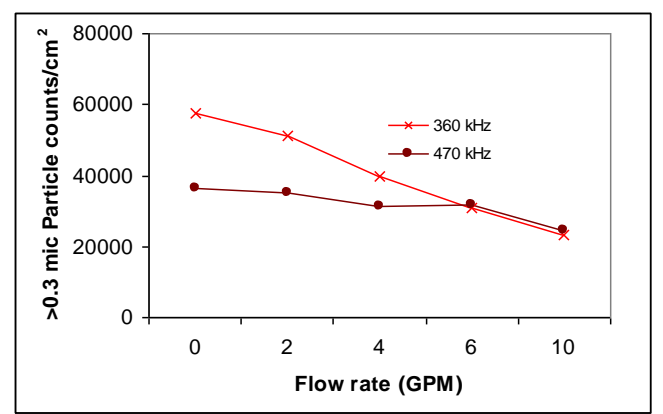

Fig. 6. Effect of re-circulation rate on cleaning for megasonic frequencies.

The effect of re-circulation rate on particle counts obtained for $360 \mathrm{kHz}$ and $470 \mathrm{kHz}$ is shown in Fig. 6. The particle count decreases (cleaning efficiency drops) very gradually with increase of flow rate. The drop in particle counts with increase of flow rate is low for $470 \mathrm{kHz}$ as compared to 360 kHz. From Fig. 5 and 6 it can be seen that the drops in particle count after 2 GPM is significantly high for ultrasonic frequency such as $58 \mathrm{kHz}$ as compared to megasonic sweeping frequencies $360 \mathrm{kHz}$ and $470 \mathrm{kHz}$. It seems that the acoustic streaming (dominant in high frequencies) was not affected much by increase of flow rate as compared to acoustic cavitation (dominant in low frequencies).

The cleaning efficiency obtained for various frequencies is shown in Fig. 7. The percent removal efficiency, $\eta(\%)$, can be calculated as follows;

$$
\eta(\%)=\left[\frac{N_{c b}-N_{c a}}{N_{c b}}\right] \times 100
$$

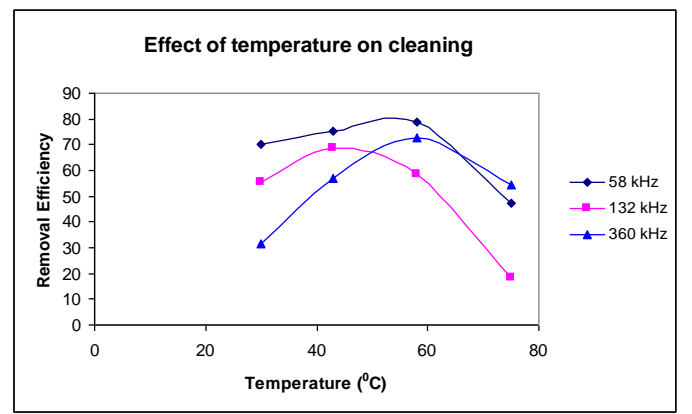

Fig. 7. Effect of temperature on cleaning efficiency.

where $N_{c b}$ is the number of particles in the extracted solution before cleaning and $N_{c a}$ is the number of particles in the extracted solution after cleaning. For any particular operating condition, three experiments were run, three removal efficiency values were measured, and their average was calculated. From Fig. 7, it can be observed that the particle removal efficiency increases with increase of temperature until $60{ }^{\circ} \mathrm{C}$ and then it start decreases with increase of temperature. The particle removal efficiency is maximum at $50-60{ }^{\circ} \mathrm{C}$. The variation of cleaning efficiency for different frequencies is higher at $30{ }^{\circ} \mathrm{C}$ and the variation is getting lower when the temperature reaches $50{ }^{\circ} \mathrm{C}$. The particle removal efficiency is high for $58 \mathrm{kHz}$ compared to all other 
frequencies tested.

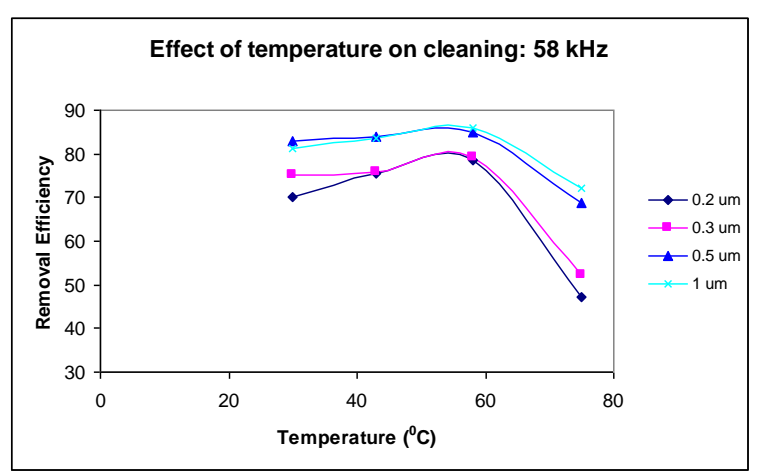

Fig. 8. Effect of temperature on particle removal efficiency for $58 \mathrm{kHz}$.

Fig. 8 shows the effect of temperature on removal efficiency for various frequencies and particle sizes. The removal efficiency is high for $1 \mu \mathrm{m}$ particles compared to 0.2 $\mu \mathrm{m}$ particles. The removal efficiency drops more significantly after $60{ }^{\circ} \mathrm{C}$ for $0.2,0.3 \mu \mathrm{m}$ particle counts compared to 0.5 and $1 \mu \mathrm{m}$ particle counts.

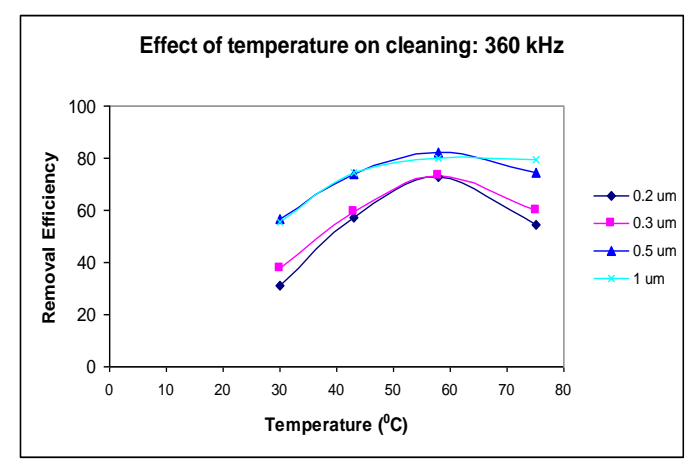

Fig. 9. Effect of temperature on particle removal efficiency for $360 \mathrm{kHz}$.

From Fig. 9, it can be observed that the removal efficiency increases linearly with increase of temperature until $65^{\circ} \mathrm{C}$ and then it decreases gradually with increase of temperature. In megasonic cleaning the cleaning mechanism is predominantly by acoustic streaming compared to acoustic cavitation. So, the increase in temperature would leads to increase in acoustic streaming velocity. The increase in streaming velocity increases the removal efficiency of particles and also avoids the re-deposition of particles.

\section{CONCLUSION}

Cavitation intensity decreases with increase of re-circulation rate. The increase in re-circulation rate when sonic on may decrease the cleaning efficiency of the system. The loss in cleaning efficiency with increase of re-circulation rate (during sonic on) is high for ultrasonic frequencies as compared to megasonic frequencies. The effect of flow rate on particle removal efficiency mainly depends on volume of the tank but not on watts/gallon of the tank. The experimental study shows that the desired re-circulation rate without affecting the sonic activity should be roughly $20-25 \%$ of the total volume of the cleaning tank for both ultrasonic and megasonic frequencies.

The cavitation intensity decreases with increase of frequency and temperature. The particle removal efficiency increases with increase of temperature until $60{ }^{\circ} \mathrm{C}$ and then it start decreases with increase of temperature for all ultrasonic frequencies tested. In case of megasonic frequency such as $360 \mathrm{kHz}$, the particle removal efficiency increases with increase of temperature until $65 \mathrm{deg} \mathrm{C}$ and then it decreases gradually with increase of temperature. We also observed that the sonic energy is more uniformly distributed for the temperature around $50-60{ }^{\circ} \mathrm{C}$. At higher temperatures around $70{ }^{\circ} \mathrm{C}$ the particle removal is not so consistent compared to particle removal at $30{ }^{\circ} \mathrm{C}$ and $50{ }^{\circ} \mathrm{C}$. So, the best ultrasonic performance should be roughly $60 \%$ of the boiling point of the liquid for effective removal of particles for most of the components. The temperature above $60 \%$ of the boiling point will decrease scrubbing force of the system thereby decrease the removal of particles. Overall, the balancing of acoustic cavitation, acoustic streaming and temperature is so important to achieve higher cleanliness for various components. A conclusion section is usually required. Although a conclusion may review the main points of the paper, do not replicate the abstract as the conclusion. A conclusion might elaborate on the importance of the work or suggest applications and extensions.

\section{ACKNOWLEDGMENT}

We wish to thank Tjung (Managing Director), Beng Hooi (Manager Sales Dept), and Research and Development team (ACT, Penang) for their kind support for this project.

\section{REFERENCES}

[1] R. Vetrimurugan and N. G. B. Hooi, "Study of ultrasonic parameters on removal of contamination from slider surface by using various cleaning chemistry," International Journal of Chemical and Environmental Engineering, vol. 3, pp. 392-396, 2012.

[2] R. Nagarajan and R. W. Welker, "Size distributions of particles extracted from disk drive parts: comparison with the MIL-STD-1246 distribution," Journal of the Institute of Environmental Science and Technology, vol. 43, no. 4, pp. 25-31, 2000.

[3] Vetrimurugan et al., "Experimental investigation of ultrasonic and megasonic frequency on cleaning of various disk drive components,' International Journal of Chemical Engineering and Applications, vol. 4, no.4, pp. 174-177, 2013.

[4] R. Nagarajan, Cavitation erosion of substrates in disk drive component cleaning: an exploratory study, Wear, 1992, pp. 75-89.

[5] R. Gouk, "Optimizing ultrasonic cleaning for disk drive components," Ultrasonic Cleaning, pp. 13-17, 1997.

[6] R. Nagarajan, R. W. Welker, and R. L. Weaver, "Evaluation of aqueous cleaning techniques for disk drive parts," in Proc. Microcontamination Conference, San Jose, CA, Oct. 16-18, 1991, pp. 312-326.

[7] W. W. Roger, R. Nagarajan, and C. E. Newberg, Contamination and ESD control in High-Technology Manufacturing, IEEE press, John Wiley and Sons, New Jersey, ch. 5, pp. 195-230, 2006

[8] J. M. Goodson, and R. Nagarajan, "Megasonic sweeping and silicon wafer cleaning," Solid State Phenomena, vol. 145-156, pp. 27-30, 2009.

[9] J. Durkee, Management of Industrial Cleaning Technology and Processes, 1st ed. Elsevier, UK, 2006, ch.1, pp. 1-41.

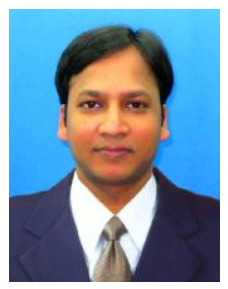

Vetrimurugan was born in India. He receive his $\mathrm{PhD}$ degree in chemical engineering from Indian Institute of Technology Madras (IITM), India in 2007. His major study is focused on ultrasonic/megasonic cleaning and ultrasonic mixing

He worked as a research officer for ISRO (Indian Space Research Organisation) project in IITM for 3 years. He worked as a cleaning and development staff 
engineer in Western Digital, Thailand for 4 years. He is currently working as a cleaning application and development manager in Crest Ultrasonics, Malaysia for past 3 years. He has published more than 20 research papers in various journals and international conferences. His current work mainly involves development of cleaning process for various customers include process optimization, equipment selection, chemistry and waste minimization. His main research areas include applications of Ultrasonic and Megasonics in diverse areas.

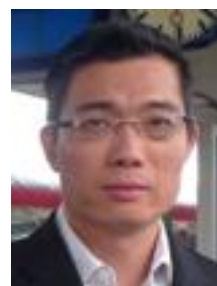

Teong Kheng Lim was born in Malaysia on 31s August 1973. He received his B.Eng degree (hons) from University Science Malaysia in 1996. His major is mechanical engineering.

He worked as a sales engineer in $3 \mathrm{M}$, Malaysia, the director in Ideal Dynamic (M) S/B, Malaysia, and the executive vice president (Asia) of Crest Group Inc. His current work involves managing operations in Asia and cleaning application development with customers of various fields.

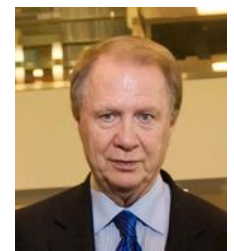

J. Michael Goodson was born in USA, who is the CEO of Crest Ultrasonics Corporation. 